\title{
10
}

\section{Interactions and Identities in UK Asylum Appeals: Lawyers and Law in a Quasi-Legal Setting}

\author{
Jessica Hambly
}

\section{Introduction}

Asylum appeals in the UK have been characterised as problematic, chaotic and inconsistent by academics, practitioners, governmental and nongovernmental organisations (Amnesty International, Still Human Still Here 2013; Asylum Aid 2011; Bail for Immigration Detainees 2006; Baillot et al. 2012; Feder 2010; Gill et al. 2015, 2016; Good 2007; Independent Asylum Commission 2008; Jubany 2011; Thomas 2011). A common focus amongst critiques is the heavy reliance on judicial discretion in the credibility assessment process, which creates space for substantial variances in terms of how appeals are decided. However, previous socio-legal research on adjudication in other contexts highlights the significance of interactions and relationships between judges, representatives and other courtroom actors (Conley and O'Barr 1990; Cowan and Hitchings 2007; Eisenstein and Jacob 1977; Fielding 2011; Kritzer 2007; Leverick and Duff 2002; Mack and Roach Anleu 2010). Asylum appeals represent a unique site of symbolic struggle, where law functions as one resource among many. This chapter explores how interactions and identities shape the asylum appeals process. It does so by focusing on the experiences and work of asylum lawyers, exploring differences in professional backgrounds, personal relationships and organisational

J. Hambly $(\bowtie)$

University of Exeter, Exeter, UK

e-mail: J.Hambly@exeter.ac.uk 
dynamics. Success in asylum appeals depends on mastering the rules of the tribunal game. This requires an appreciation of what matters alongside 'the law', and understanding how to act, engage, and mobilise resources effectively. This chapter argues that by looking at the role of interactions and identities, we gain a sense of the numerous legal and non-legal rules of engagement in asylum appeals. Concordant with Gill and Good's reflections in the Introduction to this volume, the present chapter demonstrates the multiple legal pluralities of the asylum process. This offers a new perspective on how legal values of fairness and justice in refugee determination procedures are so often subsumed by political, administrative and economic concerns to control migration.

Adjudication is a complex social process of communication and competition between actors, organisations, and institutions (Bourdieu 1987; Hawkins 2002; Moorhead and Cowan 2007). Asylum appeals, like other adjudicatory processes, are not a simple application of law to a set of facts. Law operates through relationships, networks, routines and symbols (Bourdieu 1987), and 'incorporates countless, varied and often ambiguous rules $[\ldots]$ operating with different purposes and with vastly different material and symbolic resources' (Ewick and Silbey 1998: 17). The construction of legal decisions is dependent on the personalities, preconceptions and dispositions of actors involved, but is also linked to wider social, political, economic and historical contexts (Hawkins 2003; Lipsky 1969).

Asylum representatives are said to work in the space between law and administration' (James and Killick 2012: 430). By centering the voices of asylum advocates and observing them in action at the tribunal, this chapter constructs a picture of how law functions in asylum appeals as one social force among the multiple, often conflicting, duties, goals, values, and internal logics at play in the appeals system. The quasi-legal nature of asylum appeals manifests in relationships and communication between actors situated in multiple, intersecting social fields. In this sense, asylum appeals can be conceptualised as 'semi-autonomous social fields' (Moore 1973). Such a methodological approach calls for the study of law, rules and official behavior in terms of their social context and 'connection(s) between the internal workings of an observable social field and its points of articulation with a larger setting' (Moore 1973: 742). While legal rules and procedures play a significant part in setting the rules of the game, those wishing to play (and do well) are also subject to extra-legal forces. The significance of 'semiautonomy' of the social field lies in the way norms, decisions and practices are generated both within the field, and through interactions and vulnerabilities vis-a-vis the wider social matrix (ibid.: 720). 
This chapter unpicks the dilemma whereby asylum appeals are anticipated by lawyers, and indeed appellants, to be determined within a system of 'legal rational norms', whereas what they frequently encounter is the 'highly politicised' system of immigration control (Appelqvist 2000: 87). Key to analysis here is an exploration of the significance of personal and professional identities and relationships. Emphasis shifts away from individual immigration judges, instead zooming out to the wider tribunal workgroup and the role of non-lawyers and non-law in the asylum appeals process.

\section{The UK Asylum System}

Asylum decision-making in the UK is a hybrid process; both administrative and judicial bodies deal with claims for refugee status. Protection claims are initially made to the Home Office, either on arrival to the UK at the port of entry, or, more often, at a later date in Croydon (South London). The applicant first undergoes a screening interview by an Immigration Officer (Home Office civil servant), covering basic information about their background and reasons for claiming asylum. At this stage, the individual risks being detained if their case is seen as straightforward-for example, if the Home Office wishes to invoke Dublin procedures, meaning the individual's application will be processed by the first EU Member State where fingerprints were taken or an asylum application was made. ${ }^{1}$ Alternatively, the applicant will be assigned a caseowner and given a longer, more detailed substantive interview. A legal representative may be sought at any stage, but legal aid funding is not available until the substantive interview. Even then, many asylum applicants are unable to access legal representation owing to time constraints and lack of available service providers. Based on the evidence given in interviews and any additional evidence submitted, the Home Office makes a decision on eligibility for refugee status or for a subsidiary form of protection on human rights or humanitarian grounds.

Positive decisions result in a grant of refugee status and leave to remain for five years. ${ }^{2}$ However, most claims are not successful; approximately $65 \%$

\footnotetext{
${ }^{1}$ The Detained Fast Track (DFT) procedure is currently suspended following a series of legal challenges. In January 2017 a High Court ruling confirmed the fast-track procedure in operation between 2005 and 2014 was unlawful.

${ }^{2}$ Until recently, this status would be upgraded to 'settlement' or 'indefinite leave to remain' on application after five years. Now, after the initial five years, a person with refugee status will need to undergo a 'safe return review' procedure to assess whether circumstances have changed such that they are no longer in need of protection.
} 
of initial decisions are refusals. Of these, around three quarters go on to appeal to the First Tier Tribunal (Immigration and Asylum Chamber). It is at this stage, when seeking to appeal an initial refusal, that many will look to lawyers to guide them through the more legal stage of the process. Indeed, a common reason for negative initial decisions going unchallenged is lack of access to quality legal advice, due to scarcity of legal service provision and changes to legal aid funding (Burridge and Gill 2017).

The Immigration Tribunal was originally conceived as an administrative body staffed by lay personnel. Over time, the tribunal has become increasingly judicialised (Rawlings 2005; Thomas 2003a, b). It is now run by Her Majesty's Courts and Tribunals Service and presided over by legally qualified judges appointed by the Judicial Appointments Commission. At the time of fieldwork (2012-2014) there were 19 hearing centres spread across the UK. On average, around one quarter of appeals at that time resulted in the Home Office's initial refusal being overturned. However, research has shown sizeable discrepancies in terms of success rates across different tribunals (Gill et al. 2015).

Appeals against First Tier decisions may be taken to a superior levelthe Upper Tribunal-with permission from the First Tier. If the First Tier Tribunal refuses, the appellant may apply to the Upper Tier to have that decision overturned. A small number of cases may progress outside the Tribunal system to the Court of Appeal (Court of Session in Scotland) and Supreme Court where 'important points of principle or practice' or 'other compelling reasons' are at stake ( $R$ (Cart) and ors v. Upper Tribunal and ors [2011] UKSC 28).

The asylum process has been characterised as a system caught between administration and adjudication (Thomas 2011). While civil servants at the Home Office deal with initial claims, the appeal stage marks a shift into a more legal arena. Yet actors at this level continue to be a mix of legal and non-legal professionals; even though judges are now required to have a legal background, representatives are not exclusively drawn from the legal profession. A lawyer may represent the Home Office, but most often it is a Home Office Presenting Officer (HOPO) who does the job of arguing against a protection claim (see Campbell, this volume). On the appellant's side, where a representative is present they may be regulated by one of four different professional bodies. ${ }^{3}$ Not all asylum representatives are 'lawyers', understood in the narrow sense as solicitors and barristers. The four professional bodies that

\footnotetext{
${ }^{3} \mathrm{~A}$ number of asylum appellants appear unrepresented in hearings, with the proportion of unrepresented varying significantly between tribunal locations (for detailed discussion of this see Burridge and Gill 2017).
} 
regulate asylum representation are the Solicitors Regulation Authority (SRA); Bar Standards Board (BSB); Office of the Immigration Services Commissioner (OISC); and the Chartered Institute of Legal Executives (CILEx). A person accredited by any of these four regulatory bodies may represent appellants in appeals to the tribunal. This arrangement invites a complex mix of personal, organisational and institutional pressures into asylum appeals, and contributes to the unique character of this adjudicatory setting (Thomas 2011: 48).

\section{Methodology: Studying Lawyers in Asylum Appeals}

The focus of the present work is on the perspectives and work of asylum lawyers at the tribunal. The advocacy stage of the process is often undertaken by barristers, having been instructed by solicitors or advisers.

Fieldwork consisted of in-depth, semi-structured interviews with 15 asylum advocates (11 barristers, two solicitors and two solicitors who had trained as barristers) and 25 days of observations at two different hearing centres. The interview sample size was small, and not intended to be representative, although did include a number of well-known asylum lawyers, seen as significant players in the field. Participants were recruited via a range of methods: websites (blogs and chambers), social media (twitter), personal contacts in asylum and refugee networks, and invitations to participate handed out at tribunals. While some advocates were clearly identifiable as 'cause lawyers' - doing legal work as a way to fight (what they saw as) an unjust immigration regime, others were motivated by intellectual interest, career progression or had just landed on asylum work by chance. Thus, while not representative, interview data gave rich insights into the experiences and work of a small cross-section of asylum advocates.

The tribunals were selected for several reasons. First, the advocates interviewed appeared relatively frequently at one or both of the centres. And, second, the sites had contrasting characteristics in terms of size (fewer than ten courtrooms/over 20 courtrooms), location (out of town/town centre), and appeal success rates (low end of the scale/high end of the scale). Ethical issues including consent, anonymity, risk to participants, and impact on the asylum field were given detailed consideration. For interviews, signed consent forms were used and names, workplaces, and identifying features were anonymised. Asylum hearings are generally open to the public. However, given the rarity of observers, and the close and intense nature of 
many asylum hearings, it was felt appropriate to speak to the tribunal staff in advance of hearings. In any case, advocates and judges often wanted to know who was present prior to hearings commencing. Where any objection was made owing to the nature of the appeal or vulnerability of the appellant, the hearing was not observed. Detailed notes were taken during hearings, but names, locations and any identifiable features of the case were left out. In terms of impact on the asylum field, the commitment to anonymity reflected a concern to reflect accurately the interview and observational data, without risking relations between advocates, clients and judges.

Lawyers occupy a distinct vantage point owing to their movement between different tribunals and interactions with different communities of practice. Their perspectives - how they experience their roles, the day-to-day practicalities, constraints, and pressures faced—give significant insights into variations in practices of judges, representatives and hearing centres. Rock's (1993) seminal ethnographic study of a Crown Court characterised the courthouse social world in terms of a network of concentric circles, with judges at the centre - the 'most august, sacred and protected' circle-and, at the outer reaches, civilians - those who pass through in large volumes without spending much time. Between these layers are degrees of insider status. Proximity to the inner circles depends on frequency with which actors meet 'in conditions of intimacy and interdependence', and the extent to which actors are 'sentimentally' and 'practically' embedded within the organisation (Rock 1993: 185-192). Trials under the adversarial system, argues Rock, are staged conflicts between actors playing out defined roles, where insider and outsider status can be key in terms of shaping role performance. In asylum appeals, Rock's social circles are tested by a disrupted adversarial model, whereby insider status is garnered not only by regular interactions at a particular location, but also depends on professional background and status (Gibb, this volume, as discusses the significance of space and layout to legal processes in the context of the French asylum determination system).

Previous studies from the UK, US and Canada have demonstrated the critical role played by lawyers in asylum proceedings (Bail for Immigration Detainees and Asylum Aid 2005; James and Killick 2012; Rehaag 2011; Schoenholtz and Bernstein 2008; Schoenholtz and Jacobs 2002; Thomas 2011). It has been argued that it is up to lawyers to bridge the divide between the 'fearful chaos of the refugee experience and the logical and unrealistic expectations of law and government' (Showler 2006: 210). To succeed in an asylum appeal, individuals must convince the judge of a credible account of persecution, relating to one of the Convention categories (see Sorgoni, this volume, for a critical discussion of the concept of credibility). 
However, many asylum stories are complex, fractured accounts that do not fit into the technical requirements of refugee law. Individual experiences of persecution require shaping into a legal claim for protection. Lawyers often conceptualise their role as translators, turning people's stories or problems into the language of the law:

I tell all my clients - our role is to act like an interpreter. Instead of interpreting their words from their national language into English, I translate their words into what we call the law.

But this act of translation into 'the law' is a complex process of communication and interaction. Lawyers' framing devices-their structures of knowledge, experience and meaning used when making decisions (Hawkins 2002: 52) — are built on past interactions and relationships, not only with individuals, but also with their institutional and organisational contexts (Morison and Leith 1992). It has been argued:

$[T]$ he process whereby barristers creatively construct legal information is shaped by the nature of the information available, time limitations, a consideration of how the information will be viewed by the judge/court, policy questions, their own experience of the courtroom and trials, and practical demands of the situation, rather than general caselaw principles. (Roach Anleu 2010: 93)

Although judges determine the final outcome of the asylum appeal, lawyers may also be seen as decision-makers in their own right; the process of building and presenting an asylum appeal involves numerous judgments by lawyers about what information is significant, and how others will receive it. In this sense, lawyering is a contextual and collegial endeavour. Looking at what guides divorce lawyers in their day to day work, Mather et al. (2001) identify three traditional perspectives. The first sees lawyers guided by their law school socialisation and formal professional codes ('the professional'). The second view looks to economic incentives and material conditions of work driving lawyers ('the workplace'). Third, lawyers are seen as motivated by their individual identities, values and characteristics ('the personal'). To these three outlooks, Mather et al. add a fourth - 'professionalism in practice'. This amalgamates the three traditional approaches into an enhanced model of how lawyers understand and make decisions at work. Legal practice is constituted through professional, personal and practical action. Moreover, they argue referencing Lave and Wenger's (1991) key concept, lawyers act within 'communities of practice'-loosely-defined, overlapping groups built around particular courts, law firms (or chambers) and specialisms. 
Through their communities of practice, lawyers are motivated to act according to 'common expectations and standards' (Mather et al. 2001: 6). But, as shown below, lawyers in the asylum field find themselves working within multiple fractured and intersecting communities, where aims and expectations vary according to differences in personal and professional identities. From the lawyers' perspective, a fundamental concern when it comes to the problematic nature of asylum appeals is the intrusion of political and administrative personnel and values into what (they say) ought to be an adversarial system built on juridical values. The battle between governmental rationality and legal authority in asylum appeals has received in-depth analysis by Thomas (2011). In his comprehensive review of asylum tribunal architecture, Thomas argues that:

the influence the immigration bureaucracy exerts on both the design and operation of the appeals process (means that) the structural relationship between the tribunal and the Home Office reinforces the sense that while the legal model plays an essential role in the decision process, it is a supporting role nonetheless. (2011: 55-58)

The view that asylum appeals should operate predominantly under an administrative, or bureaucratic, decision-making model where efficiency and value for money are prioritised over juridical values such as independence and procedural fairness is resisted by asylum lawyers, as will be seen below, and by the judiciary, as expounded by the outgoing President of the Immigration and Asylum Chamber of the Upper Tribunal in 2016:

We are not a statistically driven conveyor belt. Rather we, the Judges of this Chamber, are serious professionals, constantly alert to the judicial oath of office and the privilege of serving the community in the best possible ways. ${ }^{4}$

Asylum lawyers find themselves, and more importantly their clients, caught at the centre of this conflict between law, politics and administration. Asylum appeals represent a unique adjudicatory setting, where individual identities, professional actors and social worlds collide. The work and experiences of asylum advocates provide insight into the problematic nature of asylum appeals, where the significance of law, in the narrow sense, is put into doubt. To

\footnotetext{
4Justice Bernard McCloskey's section on the Immigration and Asylum Chamber in the Senior President of Tribunals' Annual Report 2016 at p. 38. Available at https://www.judiciary.uk/wp-content/ uploads/2016/02/The-Senior-President-of-Tribunals-Annual-Report-2016-final-1.pdf. Accessed 18 September 2018.
} 
understand how legal rules function in asylum appeals requires looking at the broader 'operative rules of the game' (Moore 1973: 243). Exploring the social context of asylum tribunal adjudication, we can observe the role of organisational pressures, relationships, status, and expertise in conditioning the appeals process.

\section{Lawyering in a Hostile Environment}

'It's one rule for the state and another rule for my clients'.

Asylum is a challenging area of legal practice. One immigration barrister describes this area of work as 'the hardest and most bitterly fought, most controversial, most convoluted, perhaps most poorly funded and sure most tilted battleground between the individual and the state' (Yeo 2012).

Asylum applicants face an ever-thickening web of practical challenges such as access to legal advice, criminal sanctions, and restrictions on access to healthcare, housing and other social services. Historically, UK attitudes to seeking asylum have been bound up in political, media and social paranoia surrounding 'benefit tourism', 'bogus' asylum seekers and 'clamping down on abusive claims' (Clayton 2010: 15). In 2012, the creation of a 'hostile environment' for irregular migration became official government policy. Hostile environment measures in the Immigration Acts of 2014 and 2016 included greater barriers to healthcare, housing, bank accounts, and a reduction in appeal rights against deportation. However, the ripple effect of the hostile environment is felt beyond these schemes. Asylum decision-making is frequently described as operating within a 'culture of disbelief' (Anderson et al. 2014; Griffiths 2012; Jubany 2011; Souter 2011; Schneider, this volume) and in an atmosphere of 'lawlessness' (Juss 1993; Shah 2005). In the tribunal, advocates felt the impact of broader social currents:

I've had comments from judges that say things like 'times are hard', you know, 'we can't afford to let this person become a burden on the taxpayer'. Or things like 'if we open the door to this one, when's it going to end?'. So there are definitely political judgments.

It's so political. So political. And you feel a lot of the time as though it's not about the law at all. It's about what the front page of tomorrow's Mail or tomorrow's Express is gonna look like. And that is very difficult.

I think it's such a political thing. And we talk about, you know, this Judge has got the Daily Mail tattooed on their inner eyelids. You know, they come in with all those anti-immigrant headlines very fresh in their minds, and seem to come in with a view that everybody's lying, everybody's here for the benefits, everybody's here for the NHS [...]. 
Lawyers felt their role as legal representatives was undermined by decisions based on politics of exclusion and denial, rather than legal rules and principles. This was felt more acutely in some hearing centres than others, suggesting that decision-making practices were linked to the wider tribunal community, not only individual judges.

I think there are certain cultures that grow around hearing centres. And they're not really applying the law; they're applying the kind of culture that is in that particular place.

Advocates expressed preferences for certain tribunals based on multiple, interlinked characteristics. These include the general feel of the tribunal'unpleasant', 'polite', 'bleak', 'less adversarial', 'a little bit more liberal', and more specific reasons relating to differences in decision-making practices, relationships with judges and personnel, and the practicalities of hearing centre locations. Significantly, these perceptions of differences between tribunal cultures were further linked to quality of justice; where an appeal was listed for hearing was seen as a 'massively important factor' in terms of how an appeal would run.

Going deeper into these preferences, and drawing on observational data from two tribunals, the remainder of this chapter explores differences in appeal processes by looking at the significance of lawyers' communities of practice, and ways of building, and benefiting from, insider status at the tribunal. First, insider status was gained through establishing ongoing personal relationships between actors working together frequently. This was seen as advantageous in respect of improving advocates' ability to litigate, but undermined by even closer relationships between HOPOs and judges. However, a different kind of insider status was felt through professional lawyer networks, which were seen as inaccessible to 'non-lawyer' HOPOs. The intersections of professional communities of practice with those based on locality, and the blurred lines around insider status created by these relationships, directs us to consider further the atypical nature of adversarial adjudication in asylum appeals.

\section{'If They Like You, It Helps': Personal Relationships and the Significance of Being Local}

Alongside formal law and legal training, advocates' work is shaped by routines, repetition, development of informal knowledge and status as insider or outsider in the everyday workgroup (Kritzer 1990, 1998; Morison and Leith 1992: 77-78). By looking at 'beliefs and practices shared by personnel, 
such as judges, solicitors and clerks, working in a particular court' (Leverick and Duff 2002: 43), previous court culture studies highlight how shared practices, expectations and informal norms develop among participants who work together regularly and condition adjudicatory processes (Eisenstein and Jacob 1977; Mather et al. 2001).

In asylum appeals, local networks were seen as significant in shaping advocates' interactions with tribunal staff and judges. Regular attendance at a hearing centre was advantageous where it facilitated building relationships of trust and personal rapport. Advocates found that being known by judges and Home Office representatives could afford additional reliability and legitimacy to their case. There was a suggestion that advocates who lived and worked in the same area as tribunal staff and judges were afforded 'a little bit of favour'. As one advocate remarked:

I mean, I know them [so] I think it probably does [help] a bit. Does it help the eventual decision? I hope it does. Does it help my day-to-day work? Yes. I mean, they probably accept things from me. They know I'm not going to, you know, pull the wool over their eyes.

Of the two tribunals studied here, one had a relatively small body of staff and judges, and advocates appearing regularly there felt they knew most members of the workgroup. At this location, local ties between regular participants were signified by the use of forenames or 'mate' (more often between men). Also at this location, small talk and friendly chat between local advocates, tribunal staff and Home Office personnel was common. Some advocates spoke of having close relationships with judges and others outside the tribunal workplace, often going to the same social and sporting events. Some advocates had links with the local Home Office Unit, who they would phone in advance of a hearing to clarify issues. This, they said, led to more effective and fairer hearings, because both sides were more attuned to what the other would be arguing.

To the contrary, advocates based far away from the smaller hearing centre, or who attended infrequently, found this a difficult place to represent appeals. One advocate spoke of the significance of regional accents in terms of marking out advocates as locals or outsiders, which, he said, impacted on interactions with tribunal staff. In his experience, advocates with non-local accents had experienced harsh treatment, for example having their appeals dismissed despite calling ahead to say they were late. At the smaller tribunal there was a clearer group of Rock's habitués (1993: 192-194) —advocates who were not part of the inner most circle, but who were known by tribunal staff, HOPOs and judges. The 
differences between insiders and outsiders were more marked at the smaller tribunal than the larger tribunal.

While the advantage of relationships at the smaller tribunal was linked to familiarity and trust, at the larger tribunal, with the pool of judges, staff, Home Office representatives and advocates much larger, workgroups were more fluid and relationships of familiarity harder to foster. However, knowing the judges and Home Office representatives was still seen as advantageous owing to greater predictability; advocates were better able to understand and anticipate how appeals would run.

Advocates with knowledge of particular judges said this often gave them an immediate indication of which way a hearing would go:

Generally, the more you go to the tribunals, and the more you get to know judges $(. .$.$) , when you know on the day who you've got as a judge, it tends to$ be a fairly good indicator of how your prospects will end up.

Advocates do not know the identity of the judge until arrival at the tribunal. Each morning, hearing room schedules are displayed on the wall of the common space, with the name of the Judge, the Home Office representative, appellants' representatives and the hearing type (asylum appeal, immigration appeal, or visa appeal, for example). A day's list generally comprises two or three appeals, depending on factors such as anticipated level of complexity and number of witnesses to be cross-examined. All hearings are listed for 10 a.m. At this time, usual practice is for the Judge to invite all parties into the hearing room to establish who everyone is, discuss any issues and set an order for the day's proceedings. By this point, many advocates said they already had a good idea of the outcome of their hearing, based on prior knowledge of judges as 'refusers', 'dismissers', or conversely, judges who were seen as particularly accepting of asylum claims. For instance, before one hearing, the appellant's advocate remarked to the Home Office representative 'I mean, look, we're before Judge M-. He's not gonna dismiss it, let's be honest!' That said, whereas some judges were viewed as serial refusers or allowers, others were seen as notoriously unpredictable:

When you find out who the judge is, that's gonna give you an indication as to how long you're gonna be there, if your case is 50:50 - which way it's gonna go, et cetera. And then you get some judges that just make it the most unpredictable event in the world, 'cos it's massively inconsistent [...].

These were seen as the most difficult judges to appear before. Advocates preferred predictability, even where this meant knowing there was a strong 
chance they would lose the appeal, because even in this scenario they were better able to plan their strategy and more alert to the possibilities of onward appeals. Advocates spoke of methods for collating information on different judges - lists, spreadsheets and keeping files with judges' previous determinations. Where an advocate had no prior experience with a particular judge, they might text or email around on the morning of the hearing to gauge others' experiences. In this way, the decision-making environment is conditioned by repetitive interactions between judges and representatives, not only through personal interactions but also via reputation.

Predictability was significant not only in terms of having an idea of which way the hearing would go, but also when it came to how advocates managed the appeal. Whilst the core substance of the asylum claim would remain the same, advocates adapted their performance in recognition of judicial preferences. Advocates developed a sense of how best to handle different judges, for example where judges were seen as more active or interrogatory, advocates might anticipate this, and warn their clients to be patient and tolerant of interruptions. Some judges were known to require more in terms of advocates setting out the law, whereas other judges considered themselves the experts and, as one lawyer said, 'they don't want a lecture in refugee law.' By building up experience and knowledge of other actors, advocates developed a sense of how to 'read (one's) court'. As a senior judge said to one lawyer-'well, I'm sure you know, $\mathrm{Mr} \mathrm{C}$, what you can say to some judges and what you can't say to others.'

Appellant lawyers come and go with their clients, whereas judges and Home Office representatives sit through the day's hearings together. Even where advocates felt they benefited from pre-existing workgroup relationships, their opposition— the Home Office-benefited even more so.

Sometimes you can know a judge has a certain tendency or whatever you can use to your advantage or at least mitigate it if you know it's going to be a problem. But the Home Office spend far more time there than we do, so they get to know their idiosyncrasies in even more detail than we do [...].

The judges and HOPOs certainly seem very friendly together [...] and they probably trust one another because they work together quite frequently.

HOPOs were seen as much closer to the inner circle of the tribunal. This was reinforced by the provision of permanent, private office space for the Home Office on tribunal sites, and the fact that HOPOs and judges were seen as moving in shared spaces inaccessible to lawyers. Segregated zones varied between hearing centres, but included lifts, stairways, corridors and meeting spaces. The layout and circulation routes of hearing centres 
facilitated interactions between some, while preventing interactions between others. Lawyers' access was restricted to the same as their clients: waiting rooms, public corridors and a few private consultation rooms or booths available on a first come, first served basis. That Judges and HOPOs were seen as interacting in spaces behind closed doors fuelled perceptions of the Home Office as a favoured litigant, better able to benefit from personal relationships than lawyers who, although they might be regulars, are less embedded within hearing centre communities.

Knowing each other is seen as advantageous insofar as a level of trust, personal rapport and reliability is built between actors at tribunals. Insider status is built through regular interactions and the development of social capital. However, while personal ties are perceived to play a role in shaping the course of appeals, lawyers highlight another significant form of insider status, linked to professional, rather than geographical, communities of practice.

\section{'We Recognise Our Own': Professional Relationships and the Significance of Being a Lawyer}

When you're in the tribunal there's more of a concentration on knowing that your opponent is not a lawyer [...]. As a lawyer, there's a certain approach to the law you have in relation to looking at a case, the analysis and how you present a case.

A defining element of asylum tribunal adjudication is the presence of 'non-lawyers' as representatives of the Home Office. Barristers may appear on behalf of the Home Office as part of a scheme initiated to plug a gap that left many appeals unrepresented on the Home Office side, but most appeals are done by HOPOs (see Campbell, this volume). Some have a legal background, but may not have progressed through the vocational stage of training to become a qualified barrister or solicitor. For lawyers, this made a marked difference to the way hearings were run, notably with respect to: a mismatch in professional duties; divergent organisational pressures; conflicting aims in adjudication; and imbalanced skills and work techniques.

As an officer of the court I've got duties to the court [...] it's about providing a fair hearing for the client's case. 
Barristers have an overriding 'duty to the court in the administration of justice'. This is found in the Bar Code of Conduct, and includes specific obligations to: not knowingly or recklessly mislead or attempt to mislead the court; take reasonable steps to avoid wasting the court's time; and ensure one's ability to act independently is not compromised. The barrister's duty to his or her client is subject to this primary duty to the court.

[The Home Office] don't have the duty to the court in the same way as we do. I mean, they're not lawyers. They're civil servants and they're there to do a job.

The key aim of the HOPO is to 'ensure appeals go through the system efficiently' (HOPO Training Pack: 108). HOPOs' professional standards emphasise maintaining 'a high degree of professionalism and (behaving) consistently in line with Home Office values', delivering 'robust' defence of the decision, and quick and efficient case disposal. This contrasts with the legal advocate's duty to ensure the administration of justice. HOPOs are precluded from knowingly misleading the Judge, or advancing arguments not in accordance with the law. However, conflicting professional values led advocates to view HOPOs as 'institutionalised' into Home Office culture, where the aim was always refusal rather than ensuring a fair hearing.

Lawyers were frustrated by what was seen as an undermining of core legal principles and failure to facilitate proper functioning of an adversarial process. They contrasted Home Office culture ('it's just statistics, statistics, statistics') with legal culture, in which primacy was given to rule of law and justice. HOPOs were seen by lawyers to discard legal rules as unimportant, just 'niceties of a fair hearing'.

It's very frustrating, I suppose, because it's not two-sided. There's things we have to do, you know. We can't tell the judge things about the law that we know aren't true. Whereas the Home Office have been instructed by their superiors to make submissions which the Home Office knows are unlawful [...]. It just doesn't seem fair.

Such feelings were perpetuated by evidence of the target culture at the Home Office, where the stated aim was to control 'win rates' (Home Affairs Select Committee 2012: 25), with incentives such as gift vouchers, cash bonuses and extra holidays offered to HOPOs for meeting targets (see also Campbell, this volume).

The asylum chamber is characterised by legal actors as 'a place where facts are meant to be established in a collaborative process which is not hostile 
and not meant to re-traumatise the person'. Collaboration and cooperation were seen as possible where the Home Office was represented by a barrister.

My face lights up when I realise I've got counsel on the other side because you can have a sensible conversation. And they don't seem to have this mentality that they need to always have their Home Office hat on, even when we're having counsel to counsel discussions.

Appeals with a HOPO, on the other hand, were generally more confrontational and hostile-'I am for the Secretary of State; you are for the appellant. I see no need for cooperation.'

A further distinction lies in the nature of the 'client' on either side. Part of a lawyer's duty to their client is to try and reach agreement on some things - 'So you go in there, before the judge, and say "look, can we agree on any of this?"' In asylum appeals, however, the lawyer-client relationship is not reflected on both sides.

I take instructions from my client. I advise my client. My client tells me what to do. Who instructs the HOPO? Unfortunately that's why it's difficult. Because, you know, if they had a client and you had a client and both your clients were in the room, you could say to them, 'Look, you talk to your client, I'll talk to my client, and we'll see what we can do'. But their client isn't a client. Their client's this monster; it's the Secretary of State for the Home Department.

The breakdown in the idealised adversarial model espoused by the advocate here reflects the presence of different institutional actors at the tribunal, with alternative, and often incompatible, modes of practice. Home Office materials also demonstrate this opposition in relation to ethos and language:

Whilst it is unavoidable that technical issues will have to be addressed, there is no necessity to use some of the language that the judiciary or legal professionals may use. For instance, if you are presenting an immigration case, the decision you are supporting is not your 'instructions' - it is a decision made in another business area in line with the law, the Immigration Rules and UK Border Agency policy that you are advancing in support of the strategic aims of the Agency. (HOPO Training Pack: 105)

Advocates often produce a skeleton argument prior to the hearing, outlining the main issues, evidence and any calls for further instructions on either side. The skeleton argument is passed to the judge and opposition on the 
morning of the hearing, or a couple of days before. In addition to this, advocates often liked to get a sense of who they were up against- 'to try and test the water...' so they might have an idea what to expect during crossexamination, or be able to streamline the issues for the hearing.

The good thing about being an advocate is that the advocacy doesn't start at the time of the hearing. The advocacy starts well before the hearing, because even before the hearing commences, you go in and you see your opponent.

Pre-hearing exchanges ranged from informal conversations about weekend activities, sport and mutual acquaintances, to more formal discussions of the legal issues. However, this practice was not seen as useful in all circumstances, where a particular HOPO was seen as 'unpleasant', 'confrontational', or 'frankly quite irritating', or because HOPOs lacked discretion to concede or narrow many points.

A further divergence in work techniques arises in the main body of the asylum hearing - the cross-examination. Lawyers had a strong preference for being against a similarly qualified opposition, not because it made their case any easier (on the contrary, it was often seen to make things harder), but because this gave greater predictability and integrity to proceedings. As one advocate said of the junior barristers instructed by the Home Office:

They knew how to cross-examine; they knew how to focus on the issues. So although on the one hand they were more effective as representatives, at the same time, because they were doing things in a fairer way, it was a much better hearing and the outcomes were often fairer.

Home Office barristers were seen as more polite, focused, adept at getting to the point and skillful at putting forward the case for the opposition. Crossexamination by HOPOs, on the other hand, was described as hostile, insensitive, and 'just interminable, useless, repeating the same points again and again $[\ldots]$...

One thing you'll get from counsel is that they're bound by the Bar Code of Conduct, and they know how to cross-examine. So, that's a double-edged sword. If your client is telling the truth, um, that can often work in your favour. Because $[\ldots]$ they won't ask irrelevant questions, and they won't just dig... whereas HOPOs will do that. On the other hand, with counsel it's, you know, when you're trained, you'll ask a question, get the answer you'd want and then back off. One of the things you learn in bar school, in pupillage, is: 
don't ask a question you don't know the answer to. Don't. And know when not to ask a question too many.

Fairness, as argued by the previous advocate, was also a question of predictability (knowing what your opponent was going to do) and respect for customary legal practice and training. Advocates' preference for strong representation on the opposing side was built on an idealised view of the asylum hearing as a legal exchange between two, similarly qualified, opposing factions. The adversarial system is designed 'not as an inquiry into the final truth of a matter, but as a struggle [...] between two competing, partial and incomplete cases' (Rock 1993: 31). Such a model presumes a level of equality on both sides in terms of legal skill and knowledge. A fair and effective hearing was seen as one in which the issues were properly focused and probed without resort to hostile or insensitive questioning techniques. Advocates had confidence that cross-examination would be 'proper' where they encountered a similarly trained (and regulated) opposition, even though this was more likely to highlight gaps in evidence that they would rather not have revealed. Thus, the threat identified by advocates here is to the 'ceremonial, disciplined, and staged' (Rock 1993: 27) nature of adversarial hearings. Winning appeals for clients was important. But of comparable importance was adherence to professional codes and display of good legal practice.

Advocates felt subject to double standards, with Judges' 'huge tolerance' of 'systematic flouting' of the rules and 'egregious errors' made by HOPOs reinforcing a view of the Home Office as a favoured party (Yeo 2012). This was particularly infuriating given the significant difference between the Home Office and legal aid lawyers in terms of funding and resources. The following exchange took place between an asylum barrister and judge when the Home Office appeared at the tribunal unprepared, without an evidence bundle, and requested an adjournment:

Barrister: As a matter of law, we don't need the Home Office bundle. It is down to maladministration of the Home Office. Why should [the witnesses] have given up their day of paid work for nothing? It is in the interests of justice to go ahead.

Judge: And therefore your proposal would be to go ahead part-heard?

Barrister: It seems exceptionally troubling. My client was ready for his previous appeal last year. The Home Office pulls the rug from beneath his feet and withdrew their decision. As a matter of law, all we have to prove is that my client is not returnable. Why should he have to wait a few more months just because the Home Office can't get its act together? 
Judge: I've heard what you have said. The Home Office's actions are entirely unsatisfactory. I'm sure [the $\mathrm{HOPO}$ ] will convey the dissatisfaction of the court to the Home Office.

The barrister, despite his insistence that 'as a matter of law' the hearing could proceed, failed to persuade the Judge that day. Reluctance on the part of Judges to do anything more than note dissatisfaction or annoyance was felt by other advocates, citing routine failures of the Home Office to comply with directions from the tribunal, resulting in increased time, cost and inconvenience to their clients and witnesses. But the force of law, in these instances, was rendered impotent.

Advocates' legal arguments and expertise are often not enough to secure victory in asylum appeals — not because the opposition is more skilledbut because the value of legal expertise is diminished in the asylum tribunal setting. Advocates wanted it to matter that they were better litigators, and were often quick to identify the 'non-lawyer' as an intruder in the adversarial process. Indeed, it has been argued, '(l)awyers appear to be the only occupational group to have coined a new word-nonlawyer-to divide the world between insiders and outsiders' (Mather et al. 2001: 42). But asylum appeals do not take place in an ordinary adversarial environment. Mastering the rules of the legal game-being a legal insider-is not enough.

\section{Conclusion}

The practical content of the law which emerges in the judgment is the product of a symbolic struggle between professionals possessing unequal technical skills and social influence. (Bourdieu 1987: 827)

This chapter has argued that what matters in asylum appeals is not only law, in the narrow sense of rules and procedures, but a range of interacting, and often conflicting social currents. Looking at sites of friction and struggles between conflicting institutional ideologies and organisational goals can give greater insight into an area of social life (Bourdieu and Wacquant 1992; Madson and Dezalay 2002). Furthermore, the operation of law and legal rules can be better understood by studying them in their social context and in relation to other 'non-legal' forces (Moore 1973). The tribunal occupies a site of organiational complexity, between law, politics and administration. The asymmetric nature of asylum appeals, with the inclusion of Home 
Office personnel, protocols and values, sets it apart from other traditional adjudicatory settings, such as criminal courts, which might be conceptualised as operating within the boundaries of the legal field. At the asylum tribunal, we observe multiple 'intersecting, yet incompatible fields' (Anderson et al. 2014: 13) with alternate logics and stakes of play (Calhoun 2003: 277; Harker et al. 1990; Gill and Good, this volume).

The insights gathered here relate to the stakes of play in asylum appeals. Insider status is valued; knowing the other tribunal members is seen as significant in terms of improving chances of success. This kind of social capital is more readily accumulated and deployed by those closer to the inner circles of a particular hearing centre. The other type of insider status discussed here-being legally qualified and belonging to professional lawyer circlesattracts a different kind of value. It can enhance reputation and standing within lawyer circles. The process of becoming a lawyer gives lawyers a set of rules governing language and conduct in litigation. A common understanding of rules, roles and what is acceptable conduct gives lawyers confidence; it makes the legal game more predictable and, through this, contributes to reassuring them that the game is played fairly.

However, asylum appeals at the tribunal are permeated by numerous codes, protocols, assumptions and forms of communication as a result of the history and development of the tribunal as both an overseer of administrative action and an instrument of immigration control. The divide between lawyers and non-lawyers in asylum appeals represents a struggle between actors, identities, organisations, and institutions. Advocates are open to some forms of 'extra-legal givings' - for example the benefits gained by developing relationships through interactions with judges or the opposition (particularly where this works in their favour). Yet the legitimacy of other extra-legal environmental forces is heavily resisted.

Despite tribunal reforms that affirm commitments to upholding traditional legal values and procedural guarantees, advocates experienced a system driven by scepticism of the outsider, administrative pressures to curb immigration, bureaucratic efficiency initiatives and swingeing resource cuts. This limits the effectiveness of good quality legal representation in appeals and goes some way in explaining why success rates remain at a relatively static $25 \%$ for appellants, despite significant advances in opening up Convention categories. For legal advocates, the game is about achieving fair and just consideration of protection claims according to the rules, procedures and practices of law. However, the force of law in asylum appeals is contained by other, more powerful, social forces. 


\section{References}

Amnesty International, Still Human Still Here. (2013). A Question of Credibility: Why So Many Initial Asylum Decisions Are Overturned on Appeal in the UK. Amnesty International.

Anderson, J., Hollaus, J., Lindsay, A., \& Williamson, C. (2014). The Culture of Disbelief: An Ethnographic Approach to Understanding an Under-Theorised Concept in the UK Asylum System (Refugee Studies Working Paper Series, 102). Oxford: University of Oxford.

Appelqvist, M. (2000). Refugee Law and Cause Lawyering: A Swedish Study of the Legal Profession. International Journal of Refugee Law, 12, 71-89.

Asylum Aid. (2011). Unsustainable: The Quality of Initial Decision-Making in Women's Asylum Claims.

Bail for Immigration Detainees. (2006). Working Against the Clock: Inadequacy and Injustice in the Asylum System.

Bail for Immigration Detainees and Asylum Aid. (2005). Justice Denied-Asylum and Immigration Legal Aid-A System in Crisis.

Baillot, H., Cowan, S., \& Munro, V. (2012). "Hearing the Right Gaps": Enabling and Responding to Disclosures of Sexual Violence Within the UK Asylum Process. Social and Legal Studies, 21, 269-296.

Bourdieu, P. (1987). The Force of Law: Toward a Sociology of the Juridical Field. Hastings Law Journal, 38, 814-853.

Bourdieu, P., \& Wacquant, L. J. D. (1992). An Invitation to Reflexive Sociology. Cambridge: Polity.

Burridge, A., \& Gill, N. (2017). Conveyor-Belt Justice: Precarity, Access to Justice, and Uneven Geographies of Legal Aid in UK Asylum Appeals. Antipode, 49, 23-42.

Calhoun, C. (2003). Pierre Bourdieu. In The Blackwell Companion to Major Contemporary Social Theorists (pp. 274-309). Oxford: Blackwell.

Clayton, G. (2010). Immigration and Asylum Law. Oxford: Oxford University Press.

Conley, J. M., \& O'Barr, W. M. (1990). Rules Versus Relationships: The Ethnography of Legal Discourse. Chicago and London: University of Chicago Press.

Cowan, D., \& Hitchings, E. (2007). 'Pretty Boring Stuff: District Judges and Housing Possession Proceedings. Social and Legal Studies, 16(3), 363-382.

Eisenstein, J., \& Jacob, H. (1977). Felony Justice: An Organizational Analysis of Criminal Courts. Boston: Little, Brown.

Ewick, P., \& Silbey, S. S. (1998). The Common Place of Law: Stories from Everyday Life. Chicago: University of Chicago Press.

Feder, B. (2010). A Credible Judge of Character? A Psycho-Legal Analysis of Credibility Assessments for Asylum Applicants with a History of Sexual Violence. Journal of Immigration Asylum and Nationality Law, 24, 295-323.

Fielding, N. (2011). Judges and Their Work. Social and Legal Studies, 20, 97-115. 
Gill, N., Rotter, R., Burridge, A., Allsopp, J., \& Griffiths, M. (2016). Linguistic Incomprehension in British Asylum Appeal Hearings. Anthropology Today, 32, $18-21$.

Gill, N., Rotter, R., Burridge, A., Griffiths, M., \& Allsopp, J. (2015). Inconsistency in Asylum Appeal Adjudication. Forced Migration Review, 50, 52-54.

Good, A. (2007). Anthropology and Expertise in the Asylum Courts. Oxon: Routledge-Cavendish.

Griffiths, M. (2012). "Vile Liars and Truth Distorters". Truth, Trust and the Asylum System. Anthropology Today, 28, 8-12.

Harker, R., Mahar, C., \& Wilkes, C. (Eds.). (1990). An Introduction to the Work of Pierre Bourdieu: The Practice of Theory. Basingstoke: Macmillan.

Hawkins, K. (2003). Order, Rationality and Silence: Some Reflections On Criminal Justice Decision-Making. In Exercising Discretion: Decision-Making in the Criminal Justice System and Beyond (pp. 186-220). Cullompton: Willan Publishing.

Hawkins, K. (2002). Law as Last Resort. Oxford Socio-legal Studies. Oxford University Press.

Home Affairs Select Committee. (2012). Fifth Report: The Work of the UKBA (December 2011-March 2012) (p. 25). House of Commons. Available at: https://publications.parliament.uk/pa/cm201213/cmselect/cmhaff/71/71.pdf. Accessed 18 Sep 2018.

Independent Asylum Commission. (2008). Fit for Purpose Yet? The Independent Asylum Commission's Interim Findings.

James, D., \& Killick, E. (2012). Empathy and Expertise: Case Workers and Immigration/Asylum Applicants in London. Law and Social Inquiry, 37(2), 430-455.

Jubany, O. (2011). Constructing Truths in a Culture of Disbelief: Understanding Asylum Screening from Within. International Sociolology, 26, 74-94.

Juss, S. S. (1993). Immigration, Nationality and Citizenship. London: Mansell.

Kritzer, H. (2007). Toward a Theorization of Craft. Social and Legal Studies, 16, 321-340.

Kritzer, H. M. (1998). Legal Advocacy: Lawyers and Nonlawyers at Work. Ann Arbor, MI: University of Michigan Press.

Kritzer, H. M. (1990). The Justice Broker: Lawyers and Ordinary Litigation. New York and Oxford: Oxford University Press.

Lave, J., \& Wenger, E. (1991). Situated Learning: Legitimate Peripheral Participation. Cambridge: Cambridge University Press.

Leverick, F., \& Duff, P. (2002). Court Culture and Adjournments in Criminal Cases: A Tale of Four Courts. Criminal Law Review, 39, 39-52.

Lipsky, M. (1969). Toward a Theory of Street-Level Bureaucracy (p. 48). Pap: Institute for Reasearch on Poverty.

Mack, K., \& Roach Anleu, S. (2010). Trial Courts and Adjudication. In The Oxford Handbook of Empirical Legal Research (pp. 545-570). New York: Oxford University Press. 
Madson, M. R., \& Dezalay, Y. (2002). The Power of the Legal Field: Pierre Bourdieu and the Law. In An Introduction to Law and Social Theory (pp. 189-207). Oxford and Portland: Hart.

Mather, L. M., McEwen, C. A., \& Maiman, R. J. (2001). Divorce Lawyers at Work: Varieties of Professionalism in Practice. Oxford: Oxford University Press.

Moore, S. F. (1973). Law and Social Change: The Semi-autonomous Social Field as an Appropriate Subject of Study. Law Society Review, 7, 719-746.

Moorhead, R., \& Cowan, D. (2007). Judgecraft: An Introduction. Social and Legal Studies, 16, 315-320.

Morison, J., \& Leith, P. (1992). The Barrister's World-And the Nature of Law. Milton Keynes: Open University Press.

Rawlings, R. (2005). Review, Revenge and Retreat. Modern Law Review, 68, 378-410.

Rehaag, S. (2011). The Role of Counsel in Canada's Refugee Determination System: An Empirical Assessment. Osgoode Hall Law Journal, 49, 71-116.

Roach Anleu, S. (2010). Law and Social Change (2nd ed.). London: Sage.

Rock, P. E. (1993). The Social World of an English Crown Court: Witness and Professionals in the Crown Court Centre at Wood Green. Oxford: Clarendon Press.

Schoenholtz, A., \& Bernstein, H. (2008). Improving Immigration Adjudications Through Competent Counsel. Georgetown University Law Center: Journal Legal Ethics, 21, 55-60.

Schoenholtz, A., \& Jacobs, J. (2002). The State of Asylum Representation: Ideas for Change. Georgetown University Law Center: Immigration Law Journal, 16, 739-772.

Shah, P. (Ed.). (2005). The Challenge of Asylum to Legal Systems. London and Portland: Routledge-Cavendish.

Showler, P. (2006). Refugee Sandwich: Stories of Exile and Asylum. Kingston, ON: McGill-Queen's University Press.

Souter, J. (2011). A Culture of Disbelief or Denial? Critiquing Refugee Status Determination in the United Kingdom. Oxford Monitor of Forced Migration, 1(1), 48-59.

Thomas, R. (2003a). The Impact of Judicial Review on Asylum. Public Law, 479-510.

Thomas, R. (2003b). Asylum Appeals Overhauled Again. Public Law, 260-271.

Thomas, R. (2011). Administrative Justice and Asylum Appeals: A Study of Tribunal Adjudication. Oxford: Hart.

Yeo, C. (2012). Open Season On Immigration Lawyers. Free Movement. Available at: https://www.freemovement.org.uk/open-season-on-immigration-lawyers/. Accessed 14 June 2014. 
Open Access This chapter is distributed under the terms of the Creative Commons Attribution 4.0 International License (http://creativecommons.org/licenses/ by/4.0/), which permits use, duplication, adaptation, distribution and reproduction in any medium or format, as long as you give appropriate credit to the original author(s) and the source, a link is provided to the Creative Commons license and any changes made are indicated.

The images or other third party material in this chapter are included in the work's Creative Commons license, unless indicated otherwise in the credit line; if such material is not included in the work's Creative Commons license and the respective action is not permitted by statutory regulation, users will need to obtain permission from the license holder to duplicate, adapt or reproduce the material. 